\title{
Clinical Diagnosis and Management of Resistant Hypertension
}

\author{
Costas P Tsioufis, Alexandros Kasiakogias and Dimitrios Tousoulis
}

First Cardiology Clinic, University of Athens, Hippokration Hospital, Athens, Greece

\begin{abstract}
Resistant hypertension (RHT) is variably defined as insufficient blood pressure (BP) response to multiple drug treatment. Prevalence of RHT has been thoroughly studied in the recent years, ranging from about 5 to $30 \%$ in various cohorts. Initial management of patients with apparent RHT requires identification of true treatment resistance by out-of-office BP measurements, assessment of adherence and screening for treatable causes of uncontrolled BP. Endorsement of lifestyle modifications and maximisation of the doses of a suitable regimen, preferably with the further addition of an aldosterone antagonist, are the mainstay of treatment. An invasive approach to RHT, mainly represented by renal nerve ablation, should be kept for persistently severe cases managed in a specialised hypertension centre.
\end{abstract}

\section{Keywords}

Resistant hypertension, uncontrolled blood pressure, hypertension, clinical management, diagnosis

Disclosure: CPT has received a research grant, honoraria and travel expenses from St. Jude Medical, and honoraria and travel expenses from Medtronic. AK and DT have no conflicts of interest to declare.

Received: 6 January 2016 Accepted: 5 May 2016 Citation: European Cardiology Review, 2016;11(1):12-7 DOI: 10.15420/ecr.2016:1:2

Correspondence: Costas Tsioufis, 108 Vas. Sofias Ave, 11527 Athens, Greece. E: ktsioufis@hippocratio.gr

Recent guidelines have defined resistant hypertension (RHT) as blood pressure (BP) that does not fall below $140 / 90 \mathrm{mmHg}$, despite a therapeutic strategy that includes appropriate lifestyle measures, plus a diuretic and two other antihypertensive drugs belonging to different classes at adequate doses. ${ }^{1}$ The definition of RHT has been quite arbitrary, a fact reflected on various definitions of ideal drug dosing (e.g. optimal, appropriate, maximal tolerated), the still officebased BP approach and the inclusion of patients controlled with four drugs (irrespective of dose).1,2 Better understanding of the disease in the recent years has led to different reported prevalences of RHT compared to earlier reports. Data from earlier trials documented a prevalence of $15-30 \%,{ }^{3}$ but with a more thorough evaluation of treatment resistance, especially with the use of ambulatory BP monitoring, a prevalence of less than $10 \%$ is more realistic, though higher numbers in specialised HT centres may apply. ${ }^{4,5}$

In clinical practice, causes of HT that is difficult to control may be classified into: a) incorrect characterisation as uncontrolled HT due to e.g. white-coat effect; b) inappropriate drug treatment or insufficient adherence to therapy and lifestyle measures; c) secondary forms of $\mathrm{HT}$; d) true drug RHT. RHT has been associated with increased target organ damage and increased cardiovascular risk among hypertensives and high-risk patients. ${ }^{6.7}$ Patients with persistent RHT through time have been shown to have a more than twofold risk of cardiovascular morbidity compared to patients never having RHT. ${ }^{8}$ This review will focus on the clinical management of this high-risk population; a stepwise approach that may still require rolling back to previous steps is advised (see Figure 1).

\section{Confirming the Diagnosis}

A patient with RHT represents one of the most complex cases in the field of $\mathrm{HT}$, and referral and management in a specialised $\mathrm{HT}$ clinic is considered wise. Accordingly, a thorough clinical history and physical examination can provide significant information, while a proposed set of further tests is presented in Table 1. A number of clinical correlates of RHT have been variably documented in post-hoc analysis of clinical trials and large registries. These include older age, obesity, black race, diabetes mellitus, a volume overload state, left ventricular hypertrophy, albuminuria and chronic kidney disease (CKD). ${ }^{2,4,7-9} \mathrm{~A}$ long history of HT and isolated systolic HT are often identified. Proper diagnosis of the condition needs a series of careful checkpoints.

\section{Identify Pseudoresistance}

Identification of pseudoresistance is a crucial step in the clinical diagnosis of RHT (see Table 2). It is defined as persistently uncontrolled HT at the clinic, for reasons other than true resistance to drug treatment; simple clinical tips can unmask many of these. Blood pressure should be measured according to current guidelines. A mismatch between the arm perimeter and the cuff bladder width (the latter wrongly being less than $80 \%$ of the former) is a usual cause of spurious HT, as it can lead to recorded BP higher by $10-20 \mathrm{mmHg}$ than true values. Falsely high BP may be recorded in older patients that have stiff, sclerotic arteries that remain palpable when the cuff exceeds systolic BP levels (Osler manoeuvre). A look at previous prescriptions indicating suboptimal drug combinations lacking a clear rationale, or insufficient dosing can help identify physician inertia. This may result from clinical inexperience, fear of side effects, guideline ignorance and ever-changing evidence of the optimal BP target.10,11

The most common cause of pseudoresistance, however, is the whitecoat effect that also extends to RHT. Therefore, performing ambulatory $\mathrm{BP}$ monitoring (or home BP recordings if the latter is unavailable) is a sine qua non in these patients. Analysis of 68,045 treated hypertensives in Spain showed that $12.2 \%$ of patients had apparent RHT, but of those 
Figure 1: A Clinical Management Algorithm for the Patient with Apparent Resistant Hypertension

\begin{tabular}{|c|c|c|}
\hline \multicolumn{3}{|c|}{ Evaluate } \\
\hline \multirow{2}{*}{$\begin{array}{l}\text { Exclude pseudoresistance (out-of- } \\
\text { office blood pressure } \\
\text { measurements; adherence } \\
\text { evaluation) }\end{array}$} & $\begin{array}{c}\text { Optimise three-drug regimen } \\
\text { (appropriate doses; appropriate } \\
\text { combination) }\end{array}$ & $\begin{array}{c}\text { Assess and manage secondary } \\
\text { causes (comorbidities; concurrent } \\
\text { medications) }\end{array}$ \\
\hline & Continued uncontrolled blood pressure & sure \\
\hline \multicolumn{3}{|c|}{ Patient with true treatment-resistant hypertension } \\
\hline \multicolumn{3}{|c|}{ Manage } \\
\hline $\begin{array}{c}\text { Endorse lifestyle measures: } \\
\text { weight loss and salt intake } \\
\text { reduction }\end{array}$ & $\begin{array}{l}\text { Optimise regimen (agents, doses, } \\
\text { intervals) and add fourth drug } \\
\text { (preferably spironolactone) }\end{array}$ & $\begin{array}{l}\text { Consider interventional treatments } \\
\text { if persistent true drug-resistant } \\
\text { hypertension after } 6 \text { months }\end{array}$ \\
\hline
\end{tabular}

only one-third also had true RHT confirmed with ambulatory monitoring. ${ }^{5}$ Accordingly, risk of patients with white-coat RHT is expected to be significantly lower than in true RHT but higher than controlled HT. ${ }^{6}$ Whitecoat RHT may be clinically suspected when symptoms of overtreatment or lack of target organ damage are identified.

Hypertension is a chronic asymptomatic condition that is often in need of multiple pills per day, usually for all lifetime. Adherence is traditionally defined as the extent to which a patient acts in accordance with the prescribed interval and dosing of a regimen, while persistence is the accumulation of time from initiation to discontinuation of therapy. In hypertensive patients, adherence measured by prescription refill frequency falls to less than $60 \%$ in two years. ${ }^{12}$ It is thus imperative that issues concerning these patientrelated parameters are considered in apparent RHT as regimen complexity and drug intolerance are often. An inverse relationship exists between the number of drugs and daily doses and adherence..$^{13}$ A series of methods to assess and manage adherence to treatment have been proposed in both research and clinical setting that include the $\mathrm{BP}$ response per se, regular follow-up visits, patient interview and diaries, pill counting, chemical markers of drugs, prescription refill records and electronic pill dispensers. Witnessed drug intake and further confirmation with ambulatory BP monitoring is the only method that ensures complete adherence but would not be practical outside a clinical study setting. Therapeutic drug monitoring by repeatedly measuring serum or urine drug concentrations (mostly by means of liquid chromatography-mass spectrometry) is a promising method that has been shown to be cost effective. ${ }^{14,15}$ Subsequently, confronting patients with low drug levels and providing further counselling has been reported to significantly improve BP control without drug intensification. ${ }^{16}$ Still, no optimal method exists, while even white-coat adherence has been reported as patients tend to improve their adherence before and after clinic visits. Fixed-dose combinations are endorsed in order to improve adherence, and highdose, three-drug combination pills are now widely available. ${ }^{17}$

Diagnose and Treat Causes of Insufficient BP Control Causes of secondary HT - affecting about $5-10 \%$ of the general hypertensive population - may remain undiagnosed and potentially
Table 1: Basic Testing in the Patient with Resistant Hypertension

- Ambulatory blood pressure monitoring

- 12-lead electrocardiogram

- Transthoracic echocardiogram

- complete blood count

- Serum glucose, urea, creatinine, electrolytes, lipids

- Urine analysis (protein, erythrocytes, leukocytes)

- 24-hour urine assessment for aldosterone, sodium and albumin

- Plasma aldosterone concentration and renin

- Thyroid stimulating hormone

- Renal echocardiogram

- Renal artery duplex

contribute to treatment resistance. Previously controlled HT or inexplicably high BP levels should raise suspicion. Primary hyperaldosteronism is the most common secondary cause, with a prevalence reaching $21 \%$ in a cohort of true $\mathrm{RHT}$ patients. ${ }^{18}$ It is mostly found in patients 30-60 years old with increasing BP levels. Only about $40 \%$ of patients have hypokalaemia. The plasma aldosterone-renin ratio (ARR) is considered to have higher sensitivity compared to other markers (aldosterone concentration or renin alone) for screening; yet age, concurrent drugs and method of collection affect the test results. It should be thoroughly performed according to current guidelines. ${ }^{19}$ The direct renin concentration assay, rather than plasma renin activity, is increasingly used.

A low ratio of morning plasma aldosterone concentration in $\mathrm{ng} / \mathrm{dl}$ to plasma renin activity in $\mathrm{ng} / \mathrm{ml} / \mathrm{h}$ (usual cut-off being 20-40) is a detection test that has a high negative predictive value..$^{2}$ Its accuracy, however, is affected by salt intake, concurrent drugs and time of sampling. Preparation for the measurement includes: a) correction of hyperaemia and unrestricted sodium intake; b) discontinuation of drugs affecting ARR (aldosterone antagonists should be stopped for up to 6 weeks before testing) and switching to drugs with limited effects on ARR if needed (e.g. slow release verapamil, hydralazine and a1-antagonists); c) collection of blood in the morning after patient has been out of bed for at least 2 hours and seated for 5-15 minutes. ${ }^{19} \mathrm{~A}$ positive result should be confirmed with further tests 
Table 2: Factors to be Considered in a Patient with Apparent Treatment Resistant Hypertension

\section{White-coat Effect}

Incorrect blood pressure measurement

Physician inertia

Inappropriate drug regimen

Insufficient drug doses

Adherence Issues
Complicated regimen and dosing
Financial issues
Drug side effects
Lack of disease perception
Insufficient patient education

Insufficient patient education

Renal parenchymal disease

Renal artery stenosis

Primary hyperaldosteronism

Thyroid disease

Cushing's syndrome

Pheocromocytoma

Aortic coarctation

Conditions Affecting Blood Pressure Control

Obstructive sleep apnoea

Chronic kidney disease

Significant obesity

High salt intake

High alcohol consumption

Drug-induced Resistant Hypertension

Nonsteroidal anti-inflammatory drugs

Oral contraceptives

Corticosteroids

Sympathomimetics (e.g. decongestants)

Erythropoetin

Cancer drugs (e.g. bevacizumab)

Cyclosporin

cocaine

Licorice

Ephedra

such as a captopril challenge or saline infusion test. An easy method is measurement of plasma aldosterone before and after intravenous administration of $210.9 \%$ saline in 4 hours (aldosterone levels $<5 \mathrm{ng} / \mathrm{dl}$ indicating an unlikely diagnosis and $>10 \mathrm{ng} / \mathrm{dl}$ a very likely diagnosis).

Adrenal imaging with computed tomography is recommended for subtype testing and exclusion of a cancerous form. Bilateral adrenal vein sampling is needed to identify lateralisation of aldosterone secretion in cases of an adrenal adenoma. If this is the case, laparoscopic adrenalectomy is indicated in unilateral disease. Surgery is more likely to lead to a cure in milder forms and a shorter history of hypertension..$^{21}$ In bilateral disease, such as adrenal hyperplasia, treatment is conservative with the application of mineralocorticoid receptor antagonists. Dosing of spironolactone starts low and can reach up to more than $200 \mathrm{mg}$ daily with a close follow-up for side effects. The less potent eplerenone is mostly free of antiandrogen side-effects, yet requires multiple daily doses. ${ }^{22}$

Prevalence of RHT is very high in patients with $\mathrm{CKD}_{1}{ }^{23}$ which is easily diagnosed with estimation of glomerular filtration rate and urine analysis (protein, erythrocytes, leukocytes). Further data may be gathered with a simple renal ultrasound that can image small or asymmetrical kidneys. Sodium and fluid retention, sympathetic and renin-angiotensin system (RAS) activation and functional vascular changes contribute to treatment resistance.

Renal artery stenosis is by $90 \%$ due to atherosclerotic lesions and should be suspected in patients of an older age, especially when atherosclerotic disease in other sites is present, reaching a prevalence of $70 \%$ among patients undergoing cardiac catheterisation. ${ }^{24}$ Flash pulmonary oedemas and deteriorating renal function, especially shortly after application of RAS blockers, should pose suspicion. Imaging with duplex ultrasonography or computed tomography/ magnetic resonance will set the diagnosis. The uncommon form of fibromuscular dysplasia of the renal arteries may be effectively treated with balloon angioplasty with or without stent placement. Regarding atherosclerotic stenosis, as a series of randomised controlled trials failed to show a clear benefit of renal artery stenting, ${ }^{25,26}$ management requires a close follow-up of renal function and classic drug treatment. Drugs that block the RAS are not contraindicated unless there are bilateral lesions or a unilateral lesion in a solitary kidney.

Obstructive sleep apnoea (OSA) has been extensively studied with respect to its association with $\mathrm{HT}^{27}$ The pathophysiological triad of intermittent hypoxia, ever-sustained sympathetic activation and intrathoracic pressure swings has served as a solid background for numerous studies reporting a close link between OSA and HT. Accordingly, in the setting of OSA, a close association between fluid overload, aldosterone excess and development of RHT has been proposed. ${ }^{28}$ Simple clinical tests, such as measurement of neck circumference (cut-off being $>40 \mathrm{~cm}$ ) and inspection of the uvula, as well as the use of widely accepted questionnaires (the Epworth, which assesses daytime sleepiness, and the Berlin, which assesses the clinical probability of OSA) can set suspicion in order to ask for a diagnostic polysomnographic study. ${ }^{29}$ Continuous positive airway pressure (CPAP), albeit mildly efficient in reducing BP in normotensive or mildly hypertensive patients, ${ }^{30}$ is unequivocally suggested in RHT patients with at least moderate OSA. ${ }^{31}$ However, unlike previous data, a recent randomised controlled trial failed to show a solid benefit in RHT patients. ${ }^{32}$

A long list of drugs may induce raises in BP or blunt the effects of antihypertensives mostly by promoting vasoconstriction, salt and water retention and improper neurohormonal activation. Oral contraceptives, nonsteroidal anti-inflammatory drugs and aspirin, as well as sympathomimetics, such as some anorectics and locally applied drugs for nasal congestion, should be recorded in the patients' history. In younger ages, recreational drugs such as cocaine and methamphetamines should also be considered. Herbal supplements that contain stimulants, such as ephedra, are often not reported by the patients. The BP response is largely idiosyncratic and these drugs should be withdrawn if possible to record the BP effect.

Increased salt intake is a worldwide epidemic and salt intake affects the efficacy of RAS blockers and diuretics. Patients that are traditionally more salt-sensitive are diabetics, the elderly and those with CKD. A total sodium consumption of $2400 \mathrm{mg}$ or $100 \mathrm{mmol} / \mathrm{day}$ (6 $\mathrm{g}$ or one teaspoon of salt) is advised in current guidelines. ${ }^{1}$ In a randomised cross-over study in patients with RHT, extremely low salt intake (2.8 g) compared to high salt intake (14 g) decreased BP by $23 / 9 \mathrm{mmHg} .{ }^{33} \mathrm{In}$ clinical practice, salt consumption is preferably assessed via 24 -hour 
urine sodium excretion. Normal salt excretion, indicating normal salt intake is usually defined as 24 -hour urine sodium $<220 \mathrm{mmol} / 24 \mathrm{~h}$ (5 $\mathrm{g} / 24 \mathrm{~h}$ ). Higher urine sodium excretion is associated with a need for a greater number of antihypertensive drugs to achieve sufficient BP control. ${ }^{34}$ In patients with excess salt excretion, a reduction in salt intake corresponding to a decrease by $>50 \mathrm{mmol} /$ $24 \mathrm{~h}$ (optimally $75 \mathrm{mmol} / 24 \mathrm{~h}$ ) is advised. 35

\section{Treatment}

\section{Lifestyle Measures}

Lifestyle measures as suggested by current hypertension guidelines should be pursued in all patients with RHT. ${ }^{1}$ These include sodium restriction, weight loss, an increase in physical activity, smoking cessation and reduced alcohol consumption to less than two drinks a day for men and one drink a day for women.

\section{Pharmacological Approach Optimising the Three-drug Regimen}

There are well-designed clinical guidelines for the drug management of $\mathrm{HT}$ that also apply to patients with RHT., ${ }^{1,2}$ Yet, there is a lack of trials that compare different drug treatments specifically for RHT. Different classes of drugs have different sites of action. From a mechanistic point of view, sympathetic overactivity, structural vascular changes and increased vascular resistance, renin-angiotensin-aldosterone axis activation and subclinical hypervolaemia are all target dysregulations of pharmacological treatment. ${ }^{36}$ The optimal drug combination is based on the clinical profile of each patient and the synergistic mechanisms of certain drug categories. For instance, a patient with coronary heart disease needs a beta-blocker while patients of African origin may not respond to RAS blockers. The most widely suggested first-choice, three-drug combination in RHT patients is an angiotensin converting enzyme inhibitor (or angiotensin receptor blocker), a calcium channel blocker (preferably of the dihydropyridine kind) and a thiazide diuretic. Chlorthalidone has been proposed to be superior to hydrochlorothiazide due to its longer duration of action as well as increased potency. At a dose of $25 \mathrm{mg} /$ day, it offers greater 24 -hour $\mathrm{BP}$ reduction than $50 \mathrm{mg} /$ day hydrochlorothiazide, with the greatest difference observed at night, and may be tried in certain patients with $\mathrm{RHT} .{ }^{37} \mathrm{~A}$ loop diuretic (furosemide or bumetanide preferably in multiple daily doses to avoid intermittent sodium retention) with or without a thiazide diuretic should be preferred in patients with a glomerular filtration rate below 30-40 ml/min/1.73 m².

Currently there are fixed combinations of up to three drugs and multiple dosing options in a single pill that are generally endorsed in order to improve adherence. ${ }^{17}$ However, certain drugs (e.g. captopril and centrally acting agents) require multiple daily doses. Evidence of a better BP response with evening administration of drugs in patients with RHT or OSA has also been published. ${ }^{38}$

Uncontrolled BP even after increasing the doses of a three-drug regimen to maximally tolerated levels is what defines RHT, and therefore escalation of drug doses is critical. This is particularly true for diuretics that are often under dosed. Previous clinical experience, manufacturer's guide, side effects and patient response set the maximal dose for each drug. Still, it should be kept in mind that adding a drug is more effective than increasing the dose. ${ }^{39}$ It has also long been suggested that if extracellular fluid volume is expanded, increasing the drug doses will not have any memorable effect on BP. Indeed, patients with RHT have higher aldosterone levels, lower levels of plasma renin activity and higher levels of brain and atrial natriuretic peptides compared to controls, all representing intravascular fluid retention. ${ }^{40} \mathrm{~A}$ high sodium intake, an oedematous state and a large body mass index are traditionally used clinical indices to further increase the diuretic dose with or without the addition of a potassium sparing diuretic such as amiloride. On the other hand, an increase in serum creatinine is to be expected with diuretic use, especially in patients with CKD, while it variably reflects volume depletion when increasing urea levels are also documented.

\section{Adding More Drugs}

Adding a fourth drug, or more, may be decided early in the treatment plan or after all the previous steps have been exhausted. Of all second-line drugs, an aldosterone receptor blocker (spironolactone or eplerenone in about the double dose to minimise breast pain, gynaecomastia or sexual dysfunction) is the primary choice, in order to counteract the subclinical aldosterone excess and to intensify diuresis. ${ }^{41}$ In addition, it has been shown that aldosterone levels are not sufficiently suppressed even with dual RAS blockade. ${ }^{42}$ The drug effects are reportedly independent of baseline serum aldosterone and renin levels or presence of primary hyperaldosteronism. Earlier reports showed BP decreases of up to more than $25 \mathrm{mmHg}$ with the addition of low dose spironolactone (12.5-25 mg daily), ${ }^{43}$ while the first randomised controlled trial of its kind documented a decrease of $8.6 \mathrm{mmHg}$ in 24-hour ambulatory systolic BP. ${ }^{44}$ The recently published Spironolactone versus placebo, bisoprolol, and doxazosin to determine the optimal treatment for drug-resistant hypertension (PATHWAY-2) study showed that in patients carefully evaluated for true RHT, the addition of spironolactone $25-50 \mathrm{mg}$ daily led to an approximately further $4 \mathrm{mmHg}$ and $4.5 \mathrm{mmHg}$ reduction in BP compared to doxazocin and bisoprolol respectively. ${ }^{45}$ Even these low doses of such drugs should be applied with caution in patients of older age or with CKD and potassium levels should be carefully monitored.

Other second-line drugs may be tried with variable efficacy. Alphablockers are potent vasodilators with a double benefit in patients with benign prostate hyperplasia but with the risk of orthostatic hypotension, ${ }^{46}$ while some advocate the use of both alpha- and beta-blockade (e.g. carvedilol and labetalol) at least in patients with evidence of sympathetic activation. Drug-induced vasodilation and diuresis may stimulate cathecolamine secretion, further indicating the need for beta-blockade. Direct vasodilators such as hydralazine and centrally acting agents have been traditionally used with a variable clinical benefit and issues of adherence due to the need for multiple dosing and often side effects (namely symptomatic hypotension and fluid retention). Limited data are available for newer drug classes. Initially promising results for darusentan, an endothelin receptor blocker, were accompanied by data on often side effects such as fluid retention and deteriorated renal function. ${ }^{47}$ Other drugs include the recently introduced aldosterone synthase inhibitors, canrenone and neprilysin inhibitor. ${ }^{48,49}$

\section{Interventional Treatment of Resistant Hypertension}

The submaximal rates of BP control even after drug optimisation, the solid pathophysiological concept and the advancements in technology that rekindled the interest in old practices, i.e. splachnic sympathectomy, lead to a burst in the development of and research on interventional approaches to $\mathrm{HT}^{50}$ A series of methods have been developed that include renal nerve ablation (RNA), carotid 


\section{Hypertension}

baroreceptor stimulation, central arteriovenous anastomosis, carotid bulb restoration and aortic stimulation. ${ }^{51}$ Among these, RNA is the richest method with respect to research and clinical data.

Catheter-based RNA is meant to halt efferent sympathetic signals to the kidney that lead to reduced renal flow, RAS activation and water retention, as well as afferent signals that, through the brain, augment the sympathetic action on the heart, vessels and neurohumoral loops. This is currently recommended for the treatment of patients with clinic systolic BP persistently $\geq 160 \mathrm{mmHg}$ or diastolic BP $\geq 110 \mathrm{mmHg}$, after confirming true resistance to drug treatment and as long as the patient is managed in a specialised hypertension centre. ${ }^{1.52}$

Initial data were exciting as they provided evidence of large decreases in BP (up to $30 \mathrm{mmHg}$ in office BP) with a relatively simple procedure. However, the Renal Denervation in Patients With Uncontrolled Hypertension (Symplicity HTN-3) trial, the first randomised shamcontrolled study provided results of a non-significant effect on BP even in the longer term and thus led to a decrease in the enthusiasm. ${ }^{53}$ Symplicity HTN-3 was a well-performed study but certain issues, such as medication changes during follow-up that reached a mean $40 \%$ in both active and control groups, adherence to medication, technical aspects of the procedure and subgroup characteristics, revealed that RNA is a complex therapy with an effect influenced by multiple factors. ${ }^{54}$ Technical issues are unsettled; the identification of the optimal number, depth and temperature of ablations, whether only the main renal artery or its branches or segment arteries should be ablated or whether small renal arteries $(<4 \mathrm{~mm})$, accessory or polar arteries should be treated. ${ }^{55}$ Currently a circumferential pattern of ablation covering all four quadrants as provided by basket or spirallike catheters and asymmetric as well as distal renal artery targeting is preferred. ${ }^{56}$

Upcoming studies shall test an indication for RNA for younger ages with systolic/diastolic HT without a long history of disease, that have greater sympathetic nervous system activation and a more responsive arterial wall. Effects of RNA beyond BP lowering, such as in improvement of glucose metabolism and target organ damage, have been reported. The holy grail of RNA is still the identification of ad-hoc markers of the optimal BP response. ${ }^{57}$ Changes in renal norepinephrine spillover and renal haemodynamics are painstaking and have not been tested in large trials. ${ }^{58,59}$ From a study design point of view, the Renal Denervation for Hypertension (DENER HTN) trial set a new perspective as it showed that a prespecified stepped-care antihypertensive drug treatment with improved adherence helps reveal the antihypertensive effect of RNA beyond conventional treatment. ${ }^{60}$

\section{Conclusion}

Knowledge and management of RHT has matured in recent years with the help of new epidemiological data, wider application of outof-office BP measurements and the introduction of interventional treatments. Clinical practitioners should first focus on diagnosing true RHT, defined as a properly measured office BP of $\geq 140 / 90 \mathrm{mmHg}$ with uncontrolled 24-hour BP in a patient confirmed to be taking at least a triple antihypertensive regimen (preferentially a diuretic, a RAS blocker and a calcium channel blocker) at tolerated doses. Accordingly, correct drug manipulation will help resolve some cases while others may benefit from an invasive approach.
1. Mancia G, Fagard R, Narkiewicz $K$, et al. Task Force Members. ESH/ESC Guidelines for the management of arterial hypertension: the Task Force for the management of arterial hypertension of the European Society of Hypertension (ESH) and of the European Society of Cardiology (ESC). J Hyperten 2013;31:1281-357. DOl: 10.1097/01.hjh.0000431740.32696.cC; PMID: 23817082

2. Calhoun DA, Jones D, Textor S, et al. American Heart Association Professional Education Committee. Resistan hypertension: diagnosis, evaluation, and treatment: a scientific statement from the American Heart Association Professional Education Committee of the Council for Hig Blood Pressure Research. Circulation 2008;117:e510-26. DOI: 10.1161/CIRCULATIONAHA. 108.189141; PMID: 18574054

3. Pepine CJ, Handberg EM, Cooper-DeHoff RM, et al. A calcium antagonist vs a non-calcium antagonist hypertension treatment strategy for patients with coronary artery disease. The International Verapamil-Trandolapril Study (INVEST): a randomized controlled trial. JAMA 2003;290:2805-16. PMID: 14657064

4. Brambilla G, Bombelli M, Seravalle G, et al. Prevalence and clinical characteristics of patients with true resistant hypertension in central and Eastern Europe: data from the BP-CARE study. J Hypertens 2013;31:2018-24. DOI: 10.1097/ HJH.0b013e328363823f; PMID: 23838657

5. de la Sierra A, Segura J, Banegas JR, et al. Clinical features of 8295 patients with resistant hypertension classified on the basis of ambulatory blood pressure monitoring. Hypertension 2011;57:898-902. DOI: 10.1161/ HYPERTENSIONAHA.110.168948; PMID: 21444835

6. Pierdomenico SD, Lapenna D, Bucci A, et al. Cardiovascular outcome in treated hypertensive patients with responder, masked, false resistant, and true resistant hypertension. Am J Hypertens 2005; 18:1422-8. PMID: 16280275

7. Smith SM, Gong Y, Handberg E, et al. Predictors and outcomes of resistant hypertension among patients with coronary artery disease and hypertension. J Hypertens 2014;32:635-43. DOI: 10.1097/HJH.0000000000000051; PMID: 24299915; PMCID: PMC4118668

8. Tsioufis C, Kasiakogias A, Kordalis A, et al. Dynamic resistan hypertension patterns as predictors of cardiovascular hypertension patterns as predictors of cardiovascu 2014;32:415-22. DOI: 10.1097/HJH.0000000000000023; 2014;32:415-22.
PMID: 24241057

9. Egan BM, Zhao Y, Axon RN, et al. Uncontrolled and apparent treatment resistant hypertension in the United States, 1988 to 2008. Circulation 2011,124.1046-58. DOl. 10.1161/ PMC3210066
10. Kjeldsen SE, Julius S, Dahlöf B, et al. Physician (investigator) inertia in apparent treatment-resistant hypertension insights from large randomized clinical trials. Lennart
Hansson Memorial Lecture. Blood Press 2015;24:1-6. DOI: 10.3109/08037051.2014.946787; PMID: 25162203

11. Egan BM, Zhao Y, Li J, et al. Prevalence of optimal treatment regimens in patients with apparent treatmentresistant hypertension based on office blood pressure in a community-based practice network. Hypertension 2013;62:691-7. DOI: 10.1161/HYPERTENSIONAHA.113.01448; PMID: 23918752; PMCID: PMC4066303

12. Blaschke TF, Osterberg L, Vrijens B, et al. Adherence to medications: insights arising from studies on the unreliable link between prescribed and actual drug dosing histories. Annu Rev Pharmacol Toxicol 2012;52:275-301. DOI: 10.1146/ annurev-pharmtox-011711-113247; PMID: 21942628

13. Osterberg L, Blaschke T. Adherence to medication. N Eng/J Med 2005;353:487-97. PMID: 16079372

14. Tomaszewski M, White $\mathrm{C}$, Patel $\mathrm{P}$, et al. High rates of non-adherence to antihypertensive treatment revealed by high-performance liquid chromatography-tandem mass spectrometry (HP LC-MS/MS) urine analysis. Heart 2014;100:855-61. DOI: 10.1136/heartjnl-2013-305063; PMID: 24694797; PMCID: PMC4033175

15. Chung O, Vongpatanasin W, Bonaventura K, et al. Potentia cost-effectiveness of therapeutic drug monitoring in patients with resistant hypertension. J Hypertens 2014;32:2411-21. DOI: 10.1097/HJH.0000000000000346; PMID: 25255395

16. Brinker S, Pandey A, Ayers C, et al. Therapeutic drug monitoring facilitates blood pressure control in resistant hypertension. J Am Coll Cardiol 2014;63:834-5. DOI:
10.1016/j.jacc.2013.10.067; PMID: 24315901; PMCID: PMC4374549

17. Gupta AK, Arshad S, Poulter NR. Compliance, safety, and effectiveness of fixed-dose combinations of antihypertensive agents: a meta-analysis. Hypertension 2010;55:399-407 DOl: 10.1016/j.jacc.2013.10.067; PMID: 24315901; PMCID:
PMC4374549

8. Douma S, Petidis K, Doumas M, et al. Prevalence of primary hyperaldosteronism in resistant hypertension: a retrospectiv observational study. Lancet 2008,371:1921-6

19. Funder JW, Carey RM, Fardella C, et al. Endocrine Society. Case detection, diagnosis, and treatment of patients with primary aldosteronism: an endocrine society clinical practice guideline. J Clin Endocrinol Metab 2008;93:3266-81. DOI: guideline.J Clin Endocrinol Metab 2008 .93

20. Gallay BJ, Ahmad S, Xu L, et al. Screening for primary aldosteronism without discontinuing hypertensive medications: plasma aldosterone-renin ratio. Am I Kidney Dis 2001.37:699-705. PMID: 11273868

21. Rossi GP, Bolognesi M, Rizzoni D, et al. Vascular remodeling and duration of hypertension predict outcome of adrenalectomy in primary aldosteronism patients. Hypertension 2008;51:1366-71. DOI: 10.116 HYPERTENSIONAHA. 108.111369; PMID: 1834722

22. Parthasarathy HK, Menard J, White WB, et al. A double-blind, randomized study comparing the antihypertensive effect of eplerenone and spironolactone in patients with hypertension and evidence of primary aldosteronism. J Hypertens 2011;29:980-90. DOI: 10.1097/HJH.0b013e3283455ca5; PMID: 21451421

23. de Beus E, Bots ML, van Zuilen AD, et al. MASTERPLAN Study Group. Prevalence of apparent therapy-resistant hypertension and its effect on outcome in patients with chronic kidney disease. Hypertension 2015;66:998-1005. DOI: 10.1161/HYPERTENSIONAHA.115.05694; PMID: 26351024

24. Aqel RA, Zoghbi GJ, Baldwin SA, et al. Prevalence of renal artery stenosis in high-risk veterans referred to cardiac catheterization. J Hypertens 2003;21:1157-62. PMID: 12777953

25. Wheatley K, Ives N, Gray R, et al. Revascularization vs. medical therapy for renal-artery stenosis. N Engl I Med 2009;361:1953-62. DOI: 10.1056/NEJMoa0905368; PMID: 19907042

26. Cooper CJ, Murphy TP, Cutlip DE, et al. Stenting and medica therapy for atherosclerotic renal-artery stenosis. $N$ Eng/ Med 2014:370:13-22. DOI: 10.1056/NEJMoa1310753: PMID: 24245566; PMCID: PMC4815927

27. Tsioufis C, Kasiakogias A, Thomopoulos C, et al. Managing hypertension in obstructive sleep apnea: the interplay of continuous positive airway pressure, medication and HJH.0b013e328336ed85; PMID: 20087211

28. Pimenta E, Stowasser M, Gordon RD, et al. Increased dietary sodium is related to severity of obstructive sleep apnea in sodium is related to severity of obstructive sleep apnea in patients with resistant hypertension and hyperaldosteronism. Chest 2013,143:978-83. DOI: 10.13

9. Pedrosa RP, Drager LF, Gonzaga CC, et al. Obstructive sleep apnea: the most common secondary cause of hypertension apnea: the most common secondary cause of hypertensid 2011;58:811-7. DOI: 10.1161/HYPERTENSIONAHA.111.179788; PMI: 21968750

30. Kasiakogias A, Tsioufis C, Thomopoulos C, et al. Effects of continuous positive airway pressure on blood pressure in hypertensive patients with obstructive sleep apnea: $a$ 3-year follow-up. J Hypertens 2013;31:352-60. DOI: 10.1097/ HJH.0b013e32835bdcda; PMID: 23235356 
31. Thomopoulos C, Michalopoulou H, Kasiakogias A, et al. Resistant hypertension and obstructive sleep apnea: the sparring partners. Int J Hypertens 2011:2011:947246. DOI 10.4061/2011/947246: PMID: 21274434

32. Muxfeldt ES, Margallo V, Costa LM, et al. Effects of continuous positive airway pressure treatment on clinic and ambulatory blood pressures in patients with obstructive sleep apnea and resistant hypertension: a randomized controlled trial. Hypertension 2015; 65:736-42. DOI: 10.1161/ HYPERTENSIONAHA.114.04852; PMD: 25601933

33. Pimenta E, Gaddam KK, Oparil S, et al. Effects of dietary sodium reduction on blood pressure in subjects with resistan hypertension: results from a randomized trial. Hypertension 2009;54:475-81. DOI: 10.1161/HYPERTENSIONAHA.109.131235; PMID: 19620517; PMCID: PMC2771382

34. Boudville N, Ward S, Benaroia M, et al. Increased sodium intake correlates with greater use of antihypertensive agen by subjects with chronic kidney disease. Am I Hypertens 2005;18:1300-5. PMID: 16202852

35. He FJ, Li J, Macgregor GA. Effect of longer-term modest salt reduction on blood pressure. Cochrane Database Syst Rev 2013;4:CD004937. DOI: 10.1002/14651858.CD004937.pub2; PMID: 23633321

36. Mann SJ. Drug therapy for resistant hypertension: simplifying the approach. J Clin Hypertens (Greenwich) 2011;13:120-30. DOI: 10.1111/j.1751-7176.2010.00387.X; PMID: 21272200

37. Ernst ME, Carter BL, Goerdt CJ, et al. Comparative antihypertensive effects of hydrochlorothiazide and chlorthalidone on ambulatory and office blood pressure. Hypertension 2006;47:352-8. PMID: 16432050

38. Kasiakogias A, Tsioufis C, Thomopoulos C, et al. Evening versus morning dosing of antihypertensive drugs in hypertensive patients with sleep apnoea: a cross-over study. J Hypertens 2015;33:393-400. DOI: 10.1097/ HJH.0000000000000371; PMID: 25318654

39. Wald DS, Law M, Morris JK, et al. Combination therapy versus monotherapy in reducing blood pressure: meta-analysis on 11,000 participants from 42 trials. Am J Med 2009;122:290300. DOI: 10.1016/i.amjmed.2008.09.038; PMID: 19272490

0. Gaddam KK Nishizaka MK, Pratt-Ubunama MN et at. Characterization of resistant hypertension: Association between resistant hypertension, aldosterone, and persistent intravascular volume expansion. Arch Intern persistent intravascular volume expansion. Arch Intern PMID: 18541823; PMCID: PMC2748247

41. Pimenta E, Calhoun DA. Resistant hypertension and aldosteronism. Curr Hypertens Rep 2007:9:353-9. PMID: 18177580
42. McKelvie RS, Yusuf S, Pericak D, et al. Comparison of candesartan, enalapril, and their combination in congestive heart failure: randomized evaluation of strategies for left ventricular dysfunction (RESOLVD) pilot study. The RESOLVD Pilot Study Investigators. Circulation 1999:100:1056-64. PMID: 10477530

43. Lane DA, Shah S, Beevers DG. Low-dose spironolactone in the management of resistant hypertension: a surveillance study. J Hypertens 2007;25:891-4. PMID: 17351384

44. Václavík J, Sedlák R, Plachy M, et al. Addition of spironolactone in patients with resistant arterial hypertension (ASPIRANT): a randomized, double-blind, placebo-controlled trial. Hypertension 2011;57:1069-75. DOl: 10.1161/ HYPERTENSIONAHA.111.169961; PMID: 21536989

45. Williams B, MacDonald TM, Morant S, et al. British Hypertension Society's PATHWAY Studies Group. Spironolactone versus placebo, bisoprolol, and doxazosin to determine the optimal treatment for drug-resistant hypertension (PATHWAY-2): a randomised, doubleblind, crossover trial. Lancet 2015;386:2059-68. DO 10.1016/S0140-6736(15)00257-3; PMID: 26414968; PMCID: PMC4655321

46. Chapman N, Chang CL, Dahlöf B, et al. ASCOT Investigators. Effect of doxazosin gastrointestinal therapeutic system as third-line antihypertensive therapy on blood pressure and lipids in the Anglo-Scandinavian Cardiac Outcomes Trial. Circulation 2008;118:42-8. DOl: 10.1161/ CIRCULATIONAHA. 107.737957; PMID: 18559700

47. Weber MA, Black H, Bakris G, et al. A selective endothelinreceptor antagonist to reduce blood pressure in patients with treatment-resistant hypertension: a randomised, doubleblind, placebo-controlled trial. Lancet 2009:374:1423-31. DOI: 10.1016/S0140-6736(09)61500-2; PMID: 19748665

48. Azizi M, Amar L, Menard J. Aldosterone synthase inhibition in humans. Nephrol Dial Transplant 2013;28:36-43. DOl: 10.1093/ndt/gfs388: PMID: 23045428

49. Bavishi C, Messerli FH, Kadosh B, et al. Role of neprilysin inhibitor combinations in hypertension: insights from hypertension and heart failure trials. Eur Hearts 2015:36:1967-73. D01: 10.1093/eurheart//ehv142; PMID: 25898846

50. Papademetriou V Rashidi AA, Tsioufis C, et al. Rena nerve ablion for resistant hypertension: how did

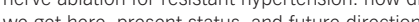
we get here, present status, and future directions Cirulation 2014;129:140051. DO1: 1011617

51. de Leeuw PW. Alnima T, Lovett $E$, et al. Bilateral or unilatera stimulation for baroreflex activation therapy. Hypertension
2015:65:187-92. DOI: 10.1161/HYPERTENSIONAHA. 114 .04492: PMID: 25331845

52. Tsioufis C, Mahfoud F, Mancia G, et al. What the interventionalist should know about renal denervation in hypertensive patients: a position paper by the ESH WG on the interventional treatment of hypertension. Eurolntervention 2014,9.1027-35. 2445727

53. Bakris GL, Townsend RR, Flack JM, et al. SYMPLICITY HTN-3 investigators. 12-month blood pressure results of catheterbased renal artery denervation for resistant hypertension: the SYMPLICITY HTN-3 trial. J Am Coll Cardiol 2015;65:1314-21. DOI: 10.1016/j.jacc.2015.01.037; PMID: 25835443

54. Papademetriou V, Tsioufis C, Doumas M. Renal denervation and Symplicity HTN-3: "Dubium sapientiae initium" (doubt is the beginning of wisdom). Circ Res 2014;115:211-4. DOI: 10.1161/CIRCRESAHA.115.304099; PMID: 24989489

55. Mahfoud F, Böhm M, Azizi M, et al. Proceedings from the European clinical consensus conference for renal denervation: considerations on future clinical trial design. Eur Heart J 2015;36:2219-27. DOI: 10.1093/eurheartj/ehv192; PMID: 25990344

56. Worthley SG, Tsioufis CP, Worthley MI, et al. Safety and efficacy of a multi-electrode renal sympathetic denervation system in resistant hypertension: the EnligHTN I trial. Eur Heart J 2013;34:2132-40. DOI: 10.1093/eurheart//eht197; PMID: 23782649; PMCID: PMC3717311

57. Kandzari DE, Bhatt DL, Brar S, et al. Predictors of blood pressure response in the SYMPLICITY HTN-3 trial. Eur Heart J 2015;36:219-27. DOI: 10.1093/eurhearti/ehu441; PMID: 25400162; PMCID: PMC4301597

58. Grassi G, Seravalle G, Brambilla G, et al. Blood pressure responses to renal denervation precede and are independent of the sympathetic and baroreflex effects. Hypertension 2015:65:1209-16. DOI: 10:1161/ HYPERTENSIONAHA.114.04823; PMID: 25824245

59. Tsioufis C, Papademetriou V, Dimitriadis K, et al. Catheterbased renal sympathetic denervation exerts acute and chronic effects on renal hemodynamics in swine. Int $J$ Cardiol 2013;168:987-92. DOI: 10.1016/j.ijcard.2012.10.038; PMID: 23164584

60. Azizi M, Sapoval M, Gosse P. et al. Renal Denervation for Hypertension (DENERHTN) investigators. Optimum and stepped care standardised antihypertensive treatment with or without renal denervation for resistant hypertension (DENERHTN): a multicentre, open-label, randomised (DENERHTN): a multicentre, open-label, randomised S0140-6736(14)61942-5; PMID: 25631070 